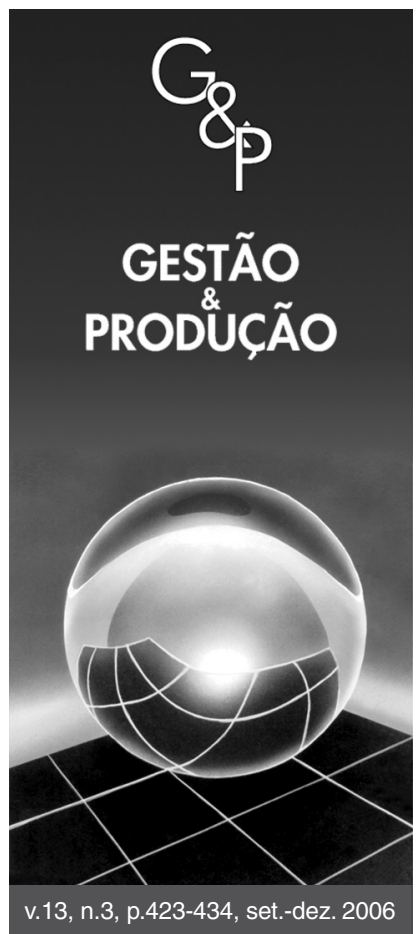

\title{
OS CONSUMIDORES VALORIZAM A COLETA DE EMBALAGENS RECICLÁVEIS? UM ESTUDO DE CASO DA LOGÍSTICA REVERSA EM UMA REDE DE HIPERMERCADOS
}

\author{
Gisele de Lorena Diniz Chaves \\ Mário Otávio Batalha \\ Departamento de Engenharia de Produção, \\ Universidade Federal de São Carlos - UFSCAR, \\ Grupo de Estudos e Pesquisas Agroindustriais, \\ C. P. 676, CEP 13565-905, São Carlos, SP, Brasil, \\ e-mail: gisele@dep.ufscar.br, dmob@ power.ufscar.br
}

Resumo

Este artigo estuda o papel e a relevância dos Centros de Coleta de embalagens recicláveis como fator de atração de clientes aos supermercados. O referencial teórico que fundamenta as análises tem como conceito central a logística reversa. A literatura estudada afirma que a implantação de mecanismos de logística reversa pelas empresas é, em grande parte, resultado da preocupação crescente dos consumidores com o meio-ambiente, os quais, portanto, tenderiam a valorizar organizações que estivessem envolvidas com a reciclagem de embalagens. Para avaliar estas questões, foi realizada uma pesquisa com 105 clientes de três lojas de uma rede supermercadista em três capitais (Rio de Janeiro, São Paulo e Belo Horizonte). Esta rede varejista estabeleceu uma aliança estratégica com uma recicladora de alumínio para o recolhimento de embalagens descartadas por meio da criação de Centros de Coleta em suas dependências. Os resultados da pesquisa apontam que a maioria dos clientes da rede de hipermercados em Belo Horizonte e São Paulo desconhecem a existência dos Centros de Coleta, diferentemente dos clientes da loja no Rio de Janeiro. No entanto, em todas as cidades, constatou-se que a existência de Centros de Coleta não é um fator de influência na escolha do local de compra pelos consumidores. Conclui-se que, para a campanha de incentivo à reciclagem de embalagens ser mais eficiente e abrangente, é necessário que a rede de hipermercados e a empresa recicladora despendam um maior esforço na divulgação dos Centros de Coleta e na motivação dos seus clientes para participarem desta iniciativa. Estas providências permitiriam que as empresas alcançassem uma imagem diferenciada junto aos consumidores.

Palavras-chave: logística reversa, hipermercado, coleta de embalagens.

\section{Introdução}

Tradicionalmente, as matérias-primas são transformadas em produtos por um ou mais segmentos industriais, que chegam aos consumidores finais pelos canais de distribuição formados. Desta forma, a logística é responsável por diminuir a lacuna entre a produção e a demanda, fornecendo bens e serviços quando, onde e na condição física que desejarem os consumidores (Ballou, 1993). O objetivo da logística é planejar e coordenar as atividades necessárias para alcançar níveis desejáveis de serviços e qualidade ao custo mais baixo possível (Christopher, 2001). Esta definição tradicional de logística empresarial vem sendo modificada nos últimos anos. A preocupação de consumidores e governos com aspectos ambientais tem premido as organizações a adotarem mecanismos logísticos que garantam o recolhimento das embalagens dos seus produtos.

Desta forma, o fluxo de materiais ao longo dos canais de suprimento deixa de ser unidirecional (fornecedo- 
res $\rightarrow$ clientes) para se tornar bidirecional (fornecedores $\leftrightarrow$ clientes). A exigência dos consumidores por um nível de serviço mais elevado - que inclui as preocupações ambientais - estaria fazendo com que as empresas implantassem e investissem em atividades de logística reversa como fator de diferenciação e fidelização dos clientes. Assim, a mudança na cultura de consumo dos clientes estaria incentivando de forma importante a logística reversa.

A maior preocupação dos governos com esta questão reflete-se no desenvolvimento de legislação adaptada aos modos de produção e consumo sustentáveis, que visem minimizar os impactos das atividades produtivas ao meio ambiente. Exemplo disso foi a elaboração da Resolução no 258 do Conselho Nacional de Meio Ambiente - CONAMA (BRASIL, 1999). Esta resolução estabelece às empresas fabricantes e importadoras de pneus a obrigação pela coleta e destino final ambientalmente adequado dos pneus inservíveis, o que obriga este segmento a sustentar políticas de logística reversa.

A logística reversa tem conquistado maior importância e espaço na operação logística das empresas, principalmente por seu potencial econômico. Nas grandes empresas norte-americanas, a logística reversa contabiliza cerca de $4 \%$ dos custos logísticos totais, um valor estimado de 35 a 42 bilhões de dólares ao ano, que representa a importância do melhoramento dos processos envolvidos com os produtos e materiais retornados (Norek, 2003; Rogers e Tibben-Lembke, 2001; Meyer, 1999).

Dentro dos principais processos envolvidos com a logística reversa, a reciclagem é um dos mais importantes. No Brasil, as embalagens PET (politereftalato de etileno) e de alumínio estão entre aquelas com maior índice de reciclagem. De acordo com o Compromisso Empresarial para Reciclagem (CEMPRE), em 2004, foram consumidas 360 mil toneladas de embalagens PET, sendo que, deste total, $48 \%$ foram recicladas, representando um crescimento de $22 \%$ em relação ao ano anterior (COMPROMISSO, 2006). Deve-se destacar que o Brasil está à frente da Europa na reciclagem deste material, já que a taxa de reciclagem naquele continente foi de $31 \%$ em 2004 (PETCORE, 2006) O País também é destaque mundial na reciclagem de embalagem de alumínio. Em 2004, pelo quarto ano consecutivo, o País lidera o ranking de reciclagem com uma taxa de $96 \%$ de material reciclado em relação ao consumido, seguido pelo Japão com $86 \%$ (COMPROMISSO, 2006).

Embora o potencial da atividade de logística reversa na economia seja econômica e ambientalmente importante, a falta de visão da atividade como geradora de vantagem competitiva às empresas compromete a estruturação e a eficiência destes canais. Recentemente, como forma de atenuar este problema, a maior empresa de reciclagem de alumínio do Brasil se uniu a uma grande rede de hipermercados numa campanha para incentivar a reciclagem de embalagens de bebidas (alumínio e PET). A expectativa das empresas era que a instalação de Centros de Coleta deste tipo de embalagem nos hipermercados geraria vantagens para ambas as organizações. A cadeia supermercadista associaria sua imagem com a preservação ambiental.

Para operacionalizar e estimular os consumidores a participarem da iniciativa, os supermercados emitiram cupons de desconto que poderiam ser utilizados para aquisição de produtos ou doação para a campanha governamental do Fome Zero. Desta forma, além de divulgar a campanha, esta ação aumentaria o fluxo de pessoas nas lojas. Presume-se que uma das vantagens da empresa recicladora seria, fundamentalmente, a de aumentar a sua captação de matéria-prima, ou seja, as embalagens recicláveis. Os custos da instalação dos Centros de Coleta implantados nas lojas da rede de hipermercados se justificariam pelo aumento de escala na coleta das embalagens e seu transporte até os Centros de Reciclagem.

Convém destacar que esta parceria entre o varejo e as empresas de reciclagem é uma iniciativa inovadora, visto que a responsabilidade pelo fluxo reverso de embalagens é normalmente do fabricante (Chaves, 2005).

Assim, a pesquisa procurou identificar se os clientes desta rede de hipermercados reconhecem os Centros de Coleta, fazem uso dos centros e, principalmente, se a presença deles os estimula a freqüentar o estabelecimento. Para isso, foi realizada uma pesquisa com 115 clientes de três lojas desta rede de hipermercados. As lojas pesquisadas estavam localizadas no Rio de Janeiro, Belo Horizonte e São Paulo.

Este artigo está dividido em sete seções. Além desta introdução, a segunda seção conceitua e caracteriza a logística reversa. Na terceira seção, a utilização estratégica dos fluxos reversos é abordada. Já a quarta seção traz alguns aspectos ligados ao comportamento de compra do consumidor no que se refere a sua escolha do local de compra. A metodologia utilizada neste estudo e os resultados da pesquisa são descritos nas seções seguintes. Na sétima seção são apresentadas algumas considerações finais.

\section{Conceituação e caracterização da logística reversa}

Nos anos 80, o conceito de logística reversa ainda estava limitado a um movimento contrário ao fluxo direto de produtos na cadeia de suprimentos. Foi na década de 90 que novas abordagens foram introduzidas e o conceito evoluiu impulsionado pelo aumento da preocupação com questões de preservação do meio ambiente. Esta pressão, induzida pelos consumidores, implicou em ações legais dos órgãos fiscalizadores. Além disso, a partir deste pe- 
ríodo, as empresas de processamento e distribuição passaram a ver a logística reversa como uma fonte importante de redução de perdas. Desta forma, as atividades de logística reversa passaram a ser utilizadas em maior intensidade nos Estados Unidos e Europa, países onde os conceitos e ferramentas clássicas de logística já eram mais disseminados.

O Conselho de Profissionais de Gestão da Cadeia de Suprimentos (Council of Supply Chain Management Professionals - CSCMP, 2005) definiu logística reversa como "um segmento especializado da logística que foca o movimento e gerenciamento de produtos e materiais após a venda e após a entrega ao consumidor. Inclui produtos retornados para reparo e/ou reembolso financeiro". Já Rogers e Tibben-Lembke (1998, p. 2) definem logística reversa como:

[...] o processo de planejamento, implementação e controle da eficiência e custo efetivo do fluxo de matérias-primas, estoques em processo, produtos acabados e as informações correspondentes do ponto de consumo para o ponto de origem com o propósito de recapturar o valor ou destinar à apropriada disposição.

A logística reversa é uma atividade ampla que envolve todas as operações relacionadas com a reutilização de produtos e materiais como as atividades logísticas de coleta, desmonte e processo de produtos e/ou materiais e peças usadas a fim de assegurar uma recuperação sustentável deles e que não prejudique o meio ambiente (REVLOG, 2005). Para que haja um fluxo reverso, existe um conjunto de atividades que uma empresa pode realizar ou terceirizar. Entre estas atividades encontram-se a coleta, separação, embalagem e expedição de itens usados, danificados ou obsoletos dos pontos de venda (ou consumo) até os locais de reprocessamento, reciclagem, revenda ou descarte (Steven, 2004). A análise dos produ- tos e materiais tem a função de definir seu estado e determinar o processo ao qual deverá se submeter. A Figura 1 mostra, de forma simplificada, o funcionamento do processo logístico reverso.

O foco de atuação da logística reversa envolve a reintrodução dos produtos ou materiais na cadeia de valor pelo ciclo produtivo ou de negócios. Portanto, o descarte do produto deve ser a última opção a ser analisada.

Pela gestão do fluxo reverso de produtos e/ou informações, a logística reversa integra os canais de distribuição reversos. Leite (2003, p. 4) define os canais de distribuição reversos como:

[...] as etapas, as formas e os meios em que uma parcela desses produtos, com pouco uso após a venda, com ciclo de vida útil ampliado ou após extinta a sua vida útil, retorna ao ciclo produtivo ou de negócios, readquirindo valor em mercados secundários pelo reuso ou reciclagem de seus materiais constituintes.

A Figura 2 ressalta como o canal reverso pode agregar valor ao sistema logístico. Observa-se que a logística reversa de pós-venda, em conjunto com a de pós-consumo, propicia benefícios à imagem corporativa, competitividade e redução de custos da empresa.

O canal de distribuição reverso de pós-consumo se caracteriza por produtos oriundos de descarte após uso e que podem ser reaproveitados de alguma forma e, somente em último caso, descartados. Já o canal de distribuição reverso de pós-venda se caracteriza pelo retorno de produtos com pouco ou nenhum uso que apresentaram problemas de responsabilidade do fabricante ou distribuidor ou, ainda, por insatisfação do consumidor com os produtos (Rogers e Tibben-Lembke, 1998).

Diversas podem ser as razões para que um produto retorne pela cadeia de suprimentos, tais como: defeito, falta de atendimento às expectativas, erro de pedidos, excesso

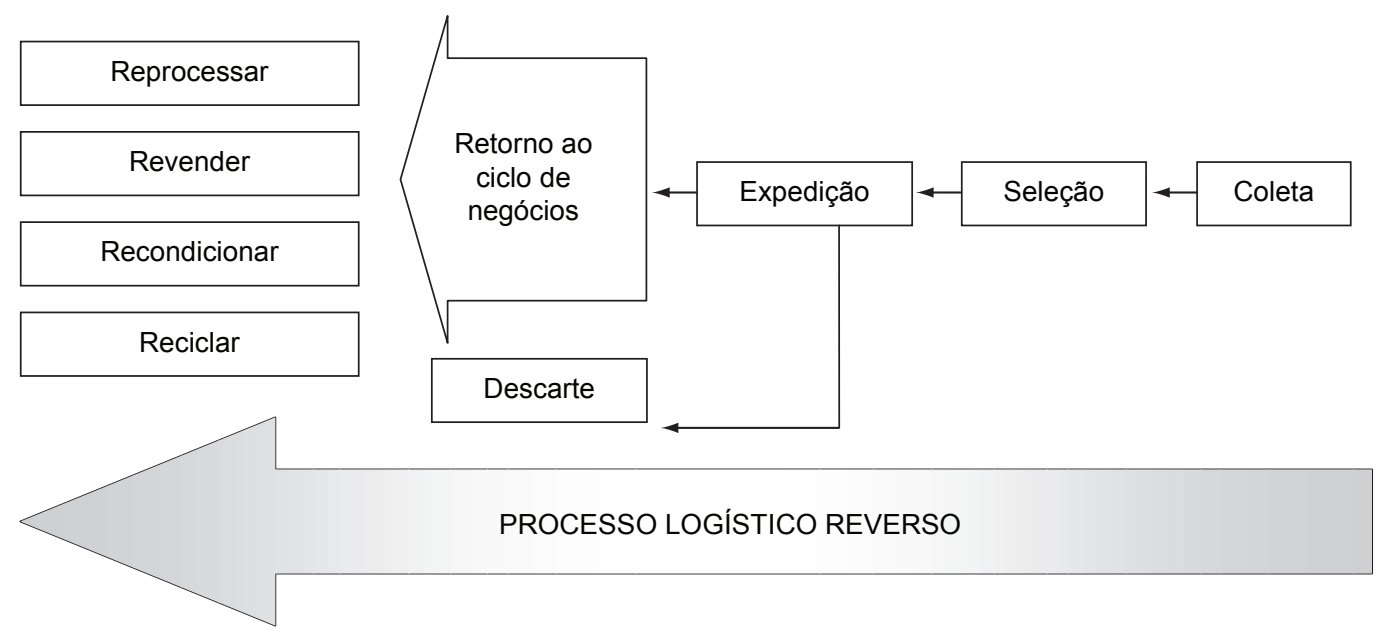

Figura 1. Atividades típicas do processo logístico reverso. Fonte: adaptado de Lacerda (2003, p. 478). 


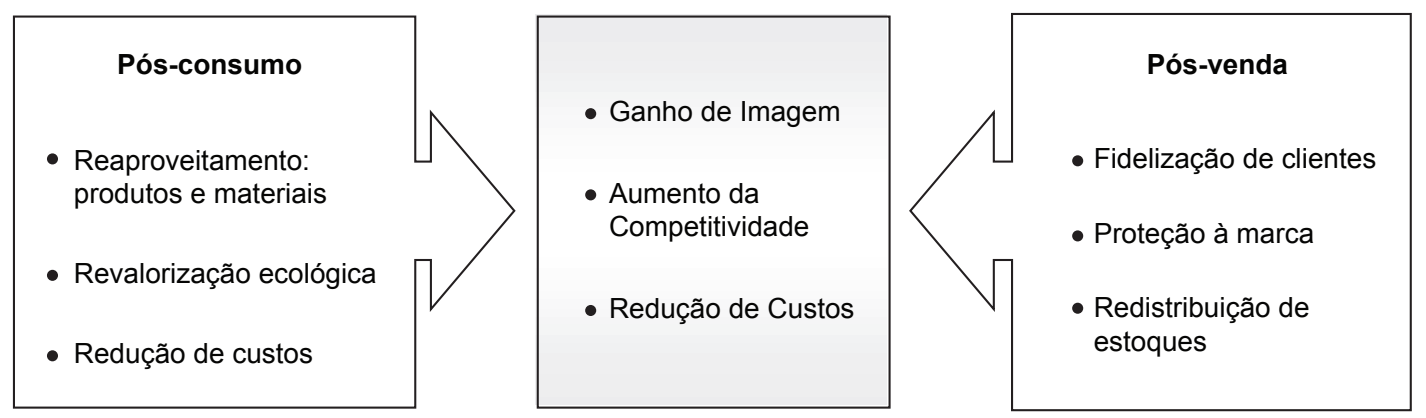

Figura 2. Fluxos reversos: agregando valor. Fonte: adaptado de Leite (2003, p. 207).

de estoque, danificação ou contaminação do produto e produtos fora de linha.

Como a logística reversa de pós-venda, a atividade relacionada ao pós-consumo também possui vantagens econômicas para a empresa que a utiliza. Leite (2003) afirma que o objetivo econômico de implantação da logística reversa de pós-consumo se deve às economias relacionadas com o aproveitamento das matérias-primas secundárias ou provenientes de reciclagem, bem como da revalorização dos bens pela reutilização e reprocesso.

Diferentemente do canal de pós-venda, de justificativa eminentemente econômica, o retorno de bens usados também tem justificativa ligada às questões ambientais e legais. Assim sendo, esta atividade é mais significativa em sociedades mais preocupadas com este tema, nas quais, via de regra, a legislação ambiental é mais rígida.

\section{A utilização da logística reversa como fator gerador de vantagem competitiva}

As bases de vantagens competitivas duradouras e sustentáveis residem em diferenças no comportamento estratégico de uma empresa e de seus concorrentes. A estratégia de uma empresa pode ser vista como sendo "a busca deliberada de um plano de ação para desenvolver e ajustar a vantagem competitiva..." (Henderson, 1998, p. 5). Assim, uma empresa deve ser capaz de criar e operacionalizar estratégias que as diferenciem de seus concorrentes e as habilitem para a obtenção de vantagens competitivas sustentáveis e defensáveis a longo prazo.

Para isso, é essencial que a empresa conheça profundamente os fatores-chave de sucesso do seu setor de atuação. Estes fatores-chave de sucesso, que são pontos possíveis de criação de vantagem competitiva, podem estar ligados às forças competitivas básicas de um setor (ameaça de entrantes, poder de negociação dos fornecedores, poder de negociação dos compradores, pressão dos produtos substitutos e a intensidade da rivalidade entre os concorrentes já existentes) (Porter, 1986).

A diferenciação de produtos e serviços é uma estratégia importante para a criação de vantagem competitiva.
Diferenciar um produto ou serviço significa torná-lo especialmente adaptado a um segmento de consumo, o qual estaria pronto a pagar mais para obtê-lo ou, ainda, utilizá-lo mais intensivamente (Kotler e Armstrong, 1998). A diferenciação dos serviços logísticos, agregando valor ou atendendo às necessidades de clientes com preocupações específicas, é uma forma importante de uma empresa obter vantagem competitiva.

A logística contribui para o sucesso das organizações não somente por propiciar aos clientes a entrega de produtos ou serviços nos padrões de tempo e espaço demandados, mas também por promover suporte ao produto após sua venda ou consumo. Uma meta comum a vários negócios é conquistar e manter os clientes pela minoração do risco e da incerteza da troca de fornecedor. Há muitos modos para desenvolver vínculos que dificultem esta troca. Um deles é o fornecedor oferecer aos seus clientes um serviço de retorno rápido e eficaz de mercadoria não vendida ou defeituosa e a habilidade de creditar os clientes de forma justa.

A logística reversa pode ser utilizada estrategicamente para permitir aos participantes do elo seguinte ao processamento na cadeia, tais como varejistas e atacadistas, reduzir o risco de comprar produtos que podem não ter vendas no período de tempo julgado conveniente. $\mathrm{O}$ uso estratégico da capacidade de logística reversa aumenta os custos de mudança de fornecedores. O aumento no nível de serviço proporcionado por esta atividade fortalece a cadeia de valor de uma empresa que, se bem configurada, reforça sua vantagem competitiva (Chaves, 2005).

Para ser visualizada e compreendida, a vantagem competitiva não pode ser analisada sob o ponto de vista da empresa como um todo. Ela se origina em atividades segmentadas como produção, projeto, marketing, logística, dentre outras. Cada atividade é fonte potencial de vantagem competitiva para a empresa. A logística reversa, por perpassar várias destas funções, pode ser responsável por vantagens competitivas ligadas mais ou menos profundamente a cada uma delas. De acordo com alguns autores (Rogers e Tibben-Lembke, 1998; Leite, 2003, Steven, 2004, Chaves, 2005), são exemplos de vantagens compe- 
titivas que podem ser obtidas pela adoção de políticas e instrumentos de logística reversa:

- Restrições ambientais: A conscientização sobre a conservação ambiental não parece ser uma tendência temporária. Este fato induz a uma reorientação duradoura da produção e do consumo que tenha entres suas premissas o crescimento sustentável. Neste contexto, a logística deve procurar a minimização do impacto ambiental, não só dos resíduos oriundos das etapas de produção e do pós-consumo, mas dos impactos ao longo do ciclo de vida dos produtos;

- Redução de custo: O reaproveitamento de materiais e a economia com embalagens retornáveis fornecem ganhos que estimulam novas iniciativas e esforços em desenvolvimento e melhoria dos processos de logística reversa. Várias indústrias, caso do alumínio, por exemplo, têm nas embalagens descartadas uma fonte de matéria-prima de qualidade e que pode ser processada a custos menores do que aqueles que seriam possíveis a partir da industrialização da bauxita (mineral de base desta indústria);

- Razões competitivas: Uma forma de ganho de vantagem competitiva frente aos concorrentes é a garantia de políticas liberais de retorno de produtos (estratégia de minimizar as barreiras para retorno e troca de produtos) que fidelizem os clientes. Dessa forma, empresas que possuem um processo de logística reversa bem gerido tendem a se sobressair no mercado, uma vez que podem atender aos seus clientes de forma melhor e diferenciada do que seus concorrentes; e

- Diferenciação da imagem corporativa: Muitas empresas estão utilizando logística reversa estrategicamente e se posicionando como empresa-cidadã, contribuindo com a comunidade e ajudando as pessoas menos favorecidas. Ressalta-se o papel social realizado por diversas empresas com cooperativas de catadores de embalagens recicláveis. Com isso, as empresas conseguem um aumento do valor da marca e, muitas vezes, de seus produtos também.

\section{O comportamento do consumidor e a escolha do local de compra}

Watson (1913, p. 159) definiu comportamento como "o conjunto das reações ou respostas que um organismo apresenta às estimulações do ambiente". Apesar da definição simples, o estudo do comportamento do consumidor abrange uma grande variedade de disciplinas interrelacionadas caracterizadas pela complexidade de seus conteúdos. No entanto, para esta pesquisa é relevante destacar em qual etapa de um modelo clássico de comportamento do consumidor a escolha do local de compra insere-se.

A Figura 3 traz o modelo de estímulo e resposta apresentado por Kotler (2000) para a compreensão do comportamento do consumidor. Ele baseia-se nas influências de marketing e ambientais, associadas às características do comprador dentro de um processo de decisão de compra. A escolha do local de compra, aspecto enfatizado nesta pesquisa, foi ressaltada na Figura 3.

Segundo Kotler (2000, p. 182), os estímulos de marketing associados a outros estímulos do ambiente, influenciam as pessoas no processo de decisão de compra, o qual está fortemente relacionado às características do comprador. Para escolher o local de compra, o cliente busca informações que o auxiliem na decisão de forma a minimizar o risco de insatisfação. Estas informações podem ser fornecidas por atividades promocionais pelo próprio varejista sobre as características do ponto de venda, por questões econômicas como renda familiar, dentre outras.

No entanto, alguns autores (Engel et al., 2000; Moura, 2005) afirmam que a imagem da loja é um dos fatores que mais influenciam o consumidor na escolha de uma loja para compra. Berman e Evans (1989) reuniram os principais componentes da imagem de uma loja, que podem ser vistos no Quadro 1.

Solomon (1999) e Peter e Olson (1999) apresentaram um modelo básico de decisão de compra do consumidor que envolve as seguintes etapas: reconhecimento do problema; busca de informação; avaliação de alternativas; compra; e pós-compra. A natureza desse processo decisório envolve as opções de compra (o que, quando e onde

\begin{tabular}{|c|c|c|c|c|}
\hline $\begin{array}{c}\text { Estímulos de } \\
\text { Marketing } \\
\end{array}$ & $\begin{array}{c}\text { Outros } \\
\text { Estímulos }\end{array}$ & $\begin{array}{l}\text { Características } \\
\text { do Comprador }\end{array}$ & $\begin{array}{c}\text { Processo de Decisão } \\
\text { do Comprador }\end{array}$ & $\begin{array}{l}\text { Decisões do } \\
\text { Comprador }\end{array}$ \\
\hline Produto & Econômicos & Culturais & Reconhecimento do problema & Escolha do Produto \\
\hline Preço & Tecnológicos & Sociais & Busca de informações & Escolha da Marca \\
\hline Ponto de Venda & Políticos & Pessoais & Avaliação & Escolha do Revendedor \\
\hline Promoção & Culturais & Psicológicas & $\begin{array}{l}\text { Decisão } \\
\text { Comportamento pós-compra }\end{array}$ & $\begin{array}{l}\text { Época da Compra } \\
\text { Ouantidade Comprada }\end{array}$ \\
\hline
\end{tabular}

Figura 3. Modelo de estímulo e resposta. Fonte: Kotler (2000, p. 183) 
Quadro 1. Principais atributos que compõem a imagem de uma loja. Fonte: Berman e Evans (1989, p. 59).

\begin{tabular}{|c|c|c|c|}
\hline Gerais & Físicos & Funcionários & Merchandise \\
\hline $\begin{array}{l}\text { Horário de funcionamento } \\
\text { Conhecimento das pessoas } \\
\text { sobre a loja } \\
\text { Extensão da cobertura } \\
\text { geográfica } \\
\text { Posicionamento de mercado } \\
\text { que deseja atingir }\end{array}$ & $\begin{array}{l}\text { Fachada da loja } \\
\text { Visibilidade da fachada } \\
\text { Arredores da loja } \\
\text { Estacionamento } \\
\text { Piso, cores, luzes, sons } \\
\text { Mobiliários } \\
\text { Largura do corredor } \\
\text { Limpeza } \\
\text { Fluxo da loja } \\
\text { Informações }\end{array}$ & $\begin{array}{l}\text { Conhecimento } \\
\text { Simpatia } \\
\text { Número de funcionários } \\
\text { Organização dos funcionários }\end{array}$ & $\begin{array}{l}\text { Sortimento } \\
\text { Qualidade } \\
\text { Disponibilidade } \\
\text { Confiança } \\
\text { Inovação } \\
\text { Uso de marcas conhecidas }\end{array}$ \\
\hline Preço & Serviços ao consumidor & Comunicação & Serviços à comunidade \\
\hline $\begin{array}{l}\text { Nível } \\
\text { Gama } \\
\text { Comparação com os } \\
\text { concorrentes } \\
\text { Freqüência de vendas }\end{array}$ & $\begin{array}{l}\text { Número } \\
\text { Nível } \\
\text { Formas de pagamento } \\
\text { Receptividade ao cliente }\end{array}$ & $\begin{array}{l}\text { Uso da mídia } \\
\text { Quantidade de propaganda } \\
\text { Conteúdo }\end{array}$ & $\begin{array}{l}\text { Quantidade } \\
\text { Nível } \\
\text { Percepção dos consumidores }\end{array}$ \\
\hline
\end{tabular}

comprar e como pagar), opções de consumo (se consome ou não, quando e como consumir) e opções de descarte (descarte ou reciclagem) (Peter e Olson, 1999). Engel et al. (2000) também adicionam ao modelo as etapas de consumo e descarte, que seriam as últimas etapas do processo decisório do consumidor.

Neste estudo, a rede hipermercadista analisada utiliza os pontos de coleta de embalagens e a promoção "Reciclagem 10, Fome Zero" como um estímulo de marketing que, considerados outros estímulos (econômicos, culturais, etc.) e as características do comprador, poderiam influenciar o processo de decisão do comprador quanto à sua escolha do local de compra e de descarte de produtos.

No entanto, para que este processo funcione, é vital que os consumidores reconheçam e valorizem a necessidade da coleta seletiva de embalagens. Em etapa posterior do processo, eles avaliarão se esta coleta é realmente relevante ambiental e socialmente. Se o julgamento dos clientes for positivo, eles retomam o processo e tomam a decisão de escolher novamente aquele ponto de venda para efetuarem suas compras.

Obviamente que somente o fator mencionado no parágrafo anterior não justifica a tomada de decisão do consumidor em relação ao seu processo de escolha do ponto de venda. Outros fatores muito importantes, como proximidade, estacionamento, variedade de produtos, preço, atendimento, comodidade por poder comprar tudo em um só local, dentre outros, devem ser necessariamente considerados.

\section{Metodologia da pesquisa}

Esta pesquisa se caracteriza por ser aplicada, de natureza qualitativa e por seu caráter exploratório. Este tipo de pesquisa tem como principais características à informalidade, a flexibilidade e a criatividade, procurando obter um primeiro contato com a situação a ser pesquisada ou um melhor conhecimento sobre o objeto em estudo (Samara e Barros, 2002).

O método de pesquisa utilizado foi o estudo de caso em uma rede hipermercadista que se uniu à maior empresa de reciclagem de alumínio do Brasil na instalação de Centros de Coleta nos hipermercados. Para delimitar este diagnóstico, foram selecionadas três lojas em três capitais (Rio de Janeiro, São Paulo e Belo Horizonte) como unidades de análise.

A amostra é do tipo probabilística, pois abrange somente os clientes da loja num determinado dia e horário escolhidos aleatoriamente. Em cada loja da rede hipermercadista, foram entrevistados, pelo menos, trinta pessoas, pois se considera que a partir deste valor tem-se uma distribuição normal (teorema do limite central) dos dados (Hoffmann, 1980; Beiguelman, 1996; Montgomery, 1997; Silva, 2001).

A coleta dos dados ocorreu mediante abordagem pessoal, utilizando como instrumento um formulário subdividido em duas partes. A primeira faz uma breve caracterização do entrevistado e a segunda procura responder às perguntas centrais da pesquisa: os clientes desta rede de hipermercados conhecem os Centros de Coleta e fazem uso dele? A existência de centros de coleta é importante quando você escolhe um ponto de venda para fazer suas compras? A Tabela 1 apresenta algumas características da amostra e do período onde ocorreu a coleta de dados.

O tratamento dos dados consistiu em análise estatística descritiva, que é representada pela distribuição de freqüência e representação gráfica. Os resultados são apresentados e discutidos na seção seguinte. 
Tabela 1. Algumas características da amostra.

\begin{tabular}{lccc}
\hline \multicolumn{1}{c}{ Loja } & Data & Horário & $\begin{array}{c}\text { Número de } \\
\text { Entrevistados }\end{array}$ \\
\hline Rio de Janeiro & $14 / 07 / 2005$ & $18: 00 \mathrm{hs}$ & 45 \\
Belo Horizonte & $20 / 07 / 2005$ & $10: 30 \mathrm{hs}$ & 30 \\
São Paulo & $02 / 09 / 2005$ & $17: 30 \mathrm{hs}$ & 30 \\
Total & - & - & $\mathbf{1 0 5}$ \\
\hline
\end{tabular}

Fonte: elaboração dos autores.

\section{Resultados e discussão}

A primeira parte da pesquisa consistiu numa caracterização da amostra composta por clientes da rede de hipermercados nas cidades do Rio de Janeiro, Belo Horizonte e São Paulo. A variável "Renda Familiar" foi excluída das análises, visto que muitos entrevistados não quiseram responder a esta questão ou não sabiam estimar a renda de todos os membros da família.

Pela Tabela 2, pode-se observar que a maioria dos clientes da loja situada no Rio de Janeiro possuía entre 41 e 60 anos, sendo que em Belo Horizonte a maioria dos entrevistados concentrou-se na faixa entre 31 e 40 anos. Já em São Paulo, grande parte dos entrevistados possuía de 31 a 40 anos e de 51 a 60 anos.

Quando se analisa a escolaridade dos entrevistados, mostrados na Tabela 3, pode-se observar que os clientes das lojas do Rio de Janeiro e de São Paulo possuem nível mais alto que os clientes da loja de Belo Horizonte. Porém, não foram realizados testes estatísticos para analisar a significância desta diferença, bem como não foi analisado o posicionamento das lojas quanto à segmentação de mercado e/ou geográfica. No entanto, pode-se dizer que tanto a loja do Rio de Janeiro quanto a de São Paulo estão localizadas em bairros de classe média e a de Belo Horizonte está localizada no centro da cidade. Estes bairros, entretanto, possuem um movimento comercial bastante intenso.

Característica de supermercados de vizinhança (ou proximidade), a maioria dos clientes $(77,8 \%)$ entrevistados na loja do Rio de Janeiro reside no mesmo bairro onde a loja se situa. Os que não residem ali trabalham em locais próximos à loja. Vale ressaltar que os hipermercados não foram concebidos para incorporar esta particularidade dos supermercados de vizinhança. No entanto, esta é a estratégia da rede hipermercadista neste caso específico.

Por outro lado, em São Paulo, o mesmo não ocorre, como pode ser observado na Tabela 4 . Do total de entrevistados, 63,3\% residem em bairros diferentes, mas trabalham próximo, ao local escolhido para compra.

Em Belo Horizonte, apenas 13,3\% dos entrevistados residem no mesmo bairro do hipermercado, já que este é um bairro mais comercial. Por este motivo, os clientes
Tabela 2. Caracterização por idade dos entrevistados da pesquisa.

\begin{tabular}{lccc}
\hline Faixa Etária & Rio de Janeiro & Belo Horizonte & São Paulo \\
\hline Até 20 anos & $6,67 \%$ & $3,3 \%$ & $0,0 \%$ \\
21 a 30 anos & $17,78 \%$ & $13,3 \%$ & $16,7 \%$ \\
31 a 40 anos & $17,78 \%$ & $40,0 \%$ & $40,0 \%$ \\
41 a 50 anos & $33,33 \%$ & $16,7 \%$ & $10,0 \%$ \\
51 a 60 anos & $24,44 \%$ & $16,7 \%$ & $30,0 \%$ \\
Mais de 60 anos & $0,0 \%$ & $10,0 \%$ & $3,3 \%$ \\
Total & $\mathbf{1 0 0 , 0 \%}$ & $\mathbf{1 0 0 , 0 \%}$ & $\mathbf{1 0 0 , 0 \%}$ \\
\hline
\end{tabular}

Fonte: Dados da pesquisa.

Tabela 3. Escolaridade dos entrevistados pela pesquisa.

\begin{tabular}{lccr}
\hline \multicolumn{1}{c}{ Escolaridade } & $\begin{array}{c}\text { Rio de } \\
\text { Janeiro }\end{array}$ & $\begin{array}{c}\text { Belo } \\
\text { Horizonte }\end{array}$ & São Paulo \\
\hline $1^{\text {o }}$ grau incompleto & $0,0 \%$ & $10,0 \%$ & $3,3 \%$ \\
$1^{\text {o }}$ grau completo & $8,9 \%$ & $3,3 \%$ & $0,0 \%$ \\
$2^{\text {o }}$ grau incompleto & $2,2 \%$ & $0,0 \%$ & $0,0 \%$ \\
$2^{\text {o }}$ grau completo & $24,4 \%$ & $36,7 \%$ & $20,0 \%$ \\
$3^{\circ}$ grau incompleto & $11,1 \%$ & $16,7 \%$ & $3,3 \%$ \\
$3^{\circ}$ grau completo & $51,1 \%$ & $30,0 \%$ & $66,7 \%$ \\
Pós-graduação & $2,2 \%$ & $3,3 \%$ & $6,7 \%$ \\
Total & $\mathbf{1 0 0 , 0 \%}$ & $\mathbf{1 0 0 , 0 \%}$ & $\mathbf{1 0 0 , 0 \%}$ \\
\hline
\end{tabular}

Fonte: Dados da pesquisa.

Tabela 4. Local de residência dos entrevistados pela pesquisa.

\begin{tabular}{lccc}
\hline Residência & $\begin{array}{c}\text { Rio de } \\
\text { Janeiro } \\
\text { - Tijuca - }\end{array}$ & $\begin{array}{c}\text { Belo } \\
\text { Horizonte } \\
\text { - Centro - }\end{array}$ & $\begin{array}{c}\text { São Paulo } \\
\text { - Itaim Bibi - }\end{array}$ \\
\hline Mesmo bairro & $77,8 \%$ & $13,3 \%$ & $36,7 \%$ \\
Bairro diferente & $22,2 \%$ & $86,7 \%$ & $63,3 \%$ \\
Total & $\mathbf{1 0 0 , 0 \%}$ & $\mathbf{1 0 0 , 0 \%}$ & $\mathbf{1 0 0 , 0 \%}$ \\
\hline
\end{tabular}

Fonte: Dados da pesquisa.

afirmaram escolher este local de compra devido à proximidade do local de trabalho.

Após a breve caracterização dos entrevistados, a segunda parte da pesquisa visa responder às questões da pesquisa. Avançando nesta direção, indagou-se se os entrevistados eram clientes assíduos da rede de hipermercados em questão. Nesta pesquisa, foi considerado cliente assíduo aquele que faz compras, pelo menos, duas vezes ao mês na loja analisada. A Tabela 5 mostra que a maioria dos entrevistados nas três lojas são clientes freqüentes, com destaque para a loja em São Paulo em que 93,3\% dos entrevistados responderam que são clientes assíduos.

Essa pergunta é importante, pois dá respaldo e valida a resposta das questões subseqüentes. Um cliente freqüente é capaz de avaliar melhor o ponto de venda e os serviços prestados que um cliente que faz visitas esporádicas à loja. 
Em seguida, foi pedido aos entrevistados que identificassem os fatores que influenciavam a escolha do local para compras. Era permitido assinalar mais de uma opção.

Dentre as variáveis apontadas pela literatura e as mais utilizadas em pesquisas (Donovan e Rossiter, 1982; Berman e Evans, 1989; Xavier, 2005) como os principais estímulos do ambiente ou que refletem estados emocionais, o fator que mais influencia os clientes entrevistados na loja localizada no Rio de Janeiro é a proximidade. Como ilustra a Figura 4, este fator foi apontado por $88,9 \%$ dos entrevistados. Este fator justifica-se em parte pelo fato de que a maioria dos clientes desta loja reside no mesmo bairro que o hipermercado.

Observa-se também que o único fator que não influencia a decisão do comprador é a existência de pontos de coleta de embalagens recicláveis. As demais variáveis de in-

Tabela 5. Nível de assiduidade dos clientes.

\begin{tabular}{cccr}
\hline Assiduidade & $\begin{array}{c}\text { Rio de } \\
\text { Janeiro }\end{array}$ & $\begin{array}{c}\text { Belo } \\
\text { Horizonte }\end{array}$ & São Paulo \\
\hline Sim & $82,2 \%$ & $76,7 \%$ & $93,3 \%$ \\
Não & $17,8 \%$ & $23,3 \%$ & $6,7 \%$ \\
Total & $\mathbf{1 0 0 , 0 \%}$ & $\mathbf{1 0 0 , 0 \%}$ & $\mathbf{1 0 0 , 0 \%}$ \\
\hline
\end{tabular}

Fonte: Dados da pesquisa. fluência na escolha do local foram indicadas, porém com menor representatividade e menor variação entre elas.

As Figuras 5 e 6 demonstram que os clientes das lojas em Belo Horizonte e São Paulo possuem um comportamento de compra semelhante. $O$ fator de maior influência na decisão acerca do local de compra continua sendo a proximidade. Em Belo Horizonte, ele foi apontado por $63,3 \%$ dos entrevistados e por 80,0\% em São Paulo como fator de influência mais importante na escolha do ponto de venda.

Neste caso, como a maioria dos entrevistados não reside no mesmo bairro do hipermercado, mas trabalha próximo a ele, este fator não destacou-se mais pronunciadamente dos demais, como no caso dos clientes da loja do Rio de Janeiro. A variável preço foi a segunda mais indicada por $40 \%$ dos entrevistados nas duas lojas.

A variedade de produtos foi o terceiro no ranking de fatores de influência na escolha do local de compra, sendo indicado por $16,7 \%$ e $20,0 \%$ dos entrevistados em Belo Horizonte e São Paulo, respectivamente.

Juntamente como a proximidade ao local de trabalho, os fatores preço e variedade dos produtos fazem com que os consumidores prefiram a referida loja da rede de hipermercados a um supermercado de vizinhança. Segundo Churchill (2003, p. 164) este intercâmbio entre empresa e

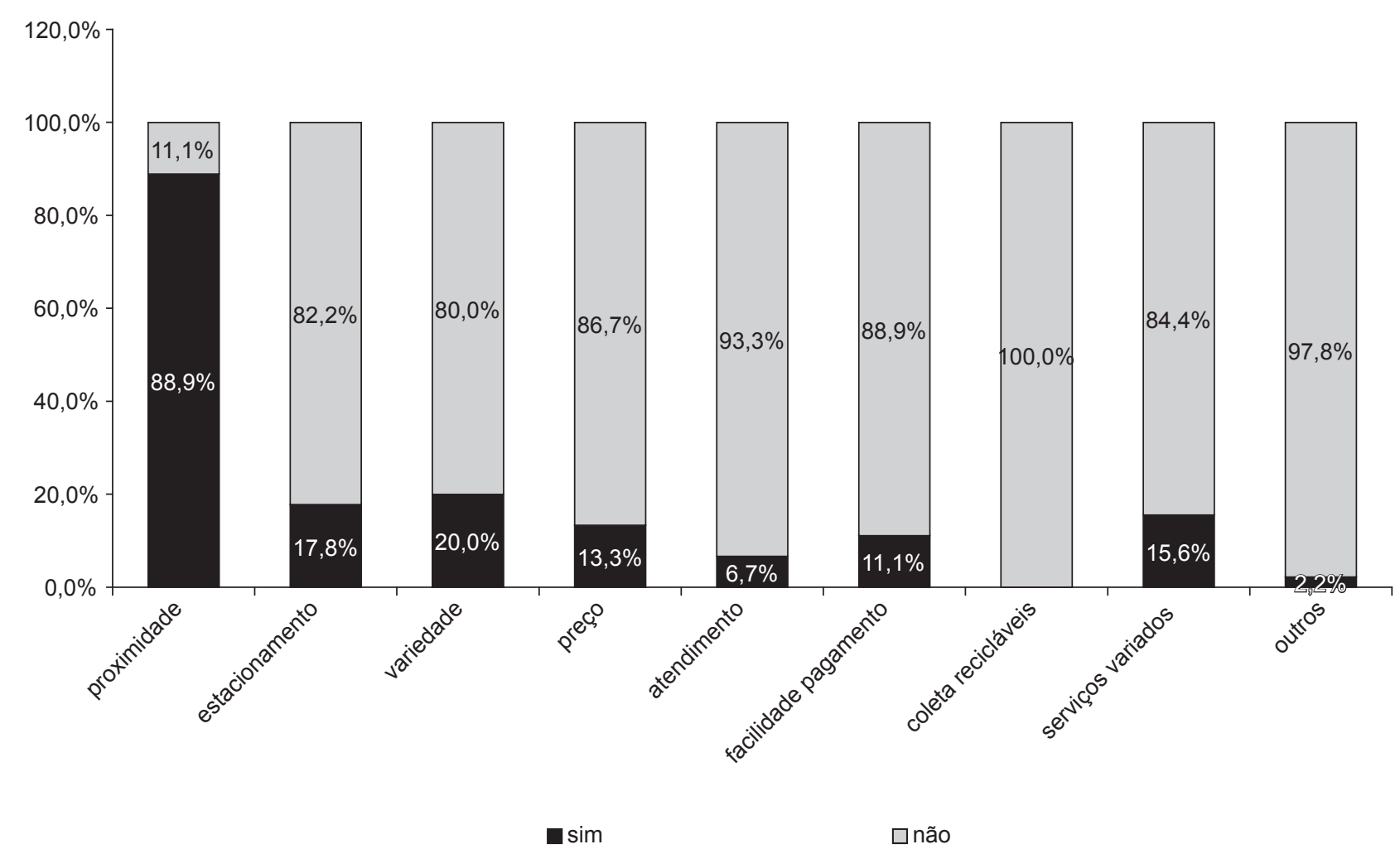

Figura 4. Fatores que influenciam a escolha do local de compra para os consumidores no Rio de Janeiro. Fonte: Dados da pesquisa. 


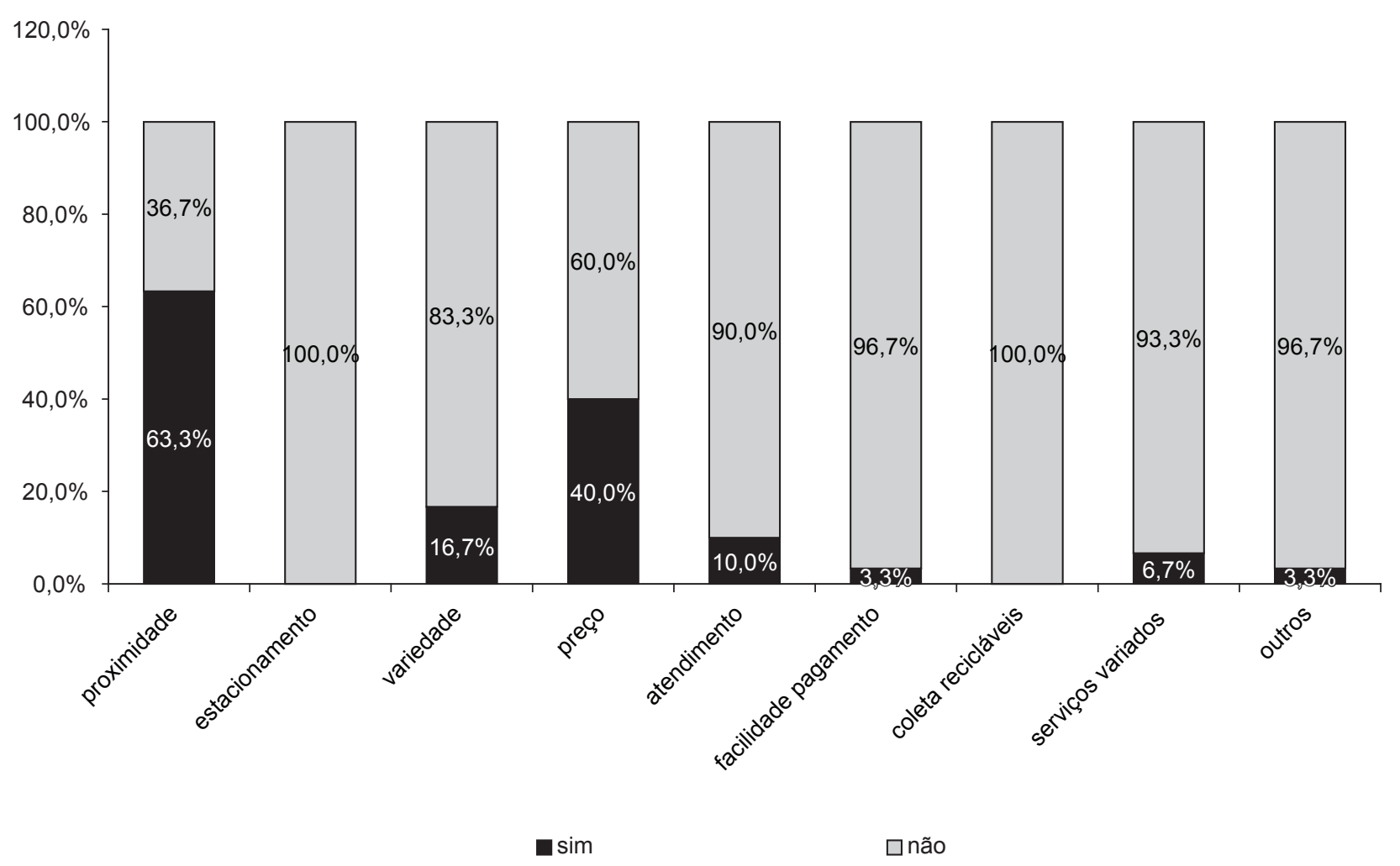

Figura 5. Fatores que influenciam a escolha do local de compra para os consumidores em Belo Horizonte. Fonte: Dados da pesquisa.

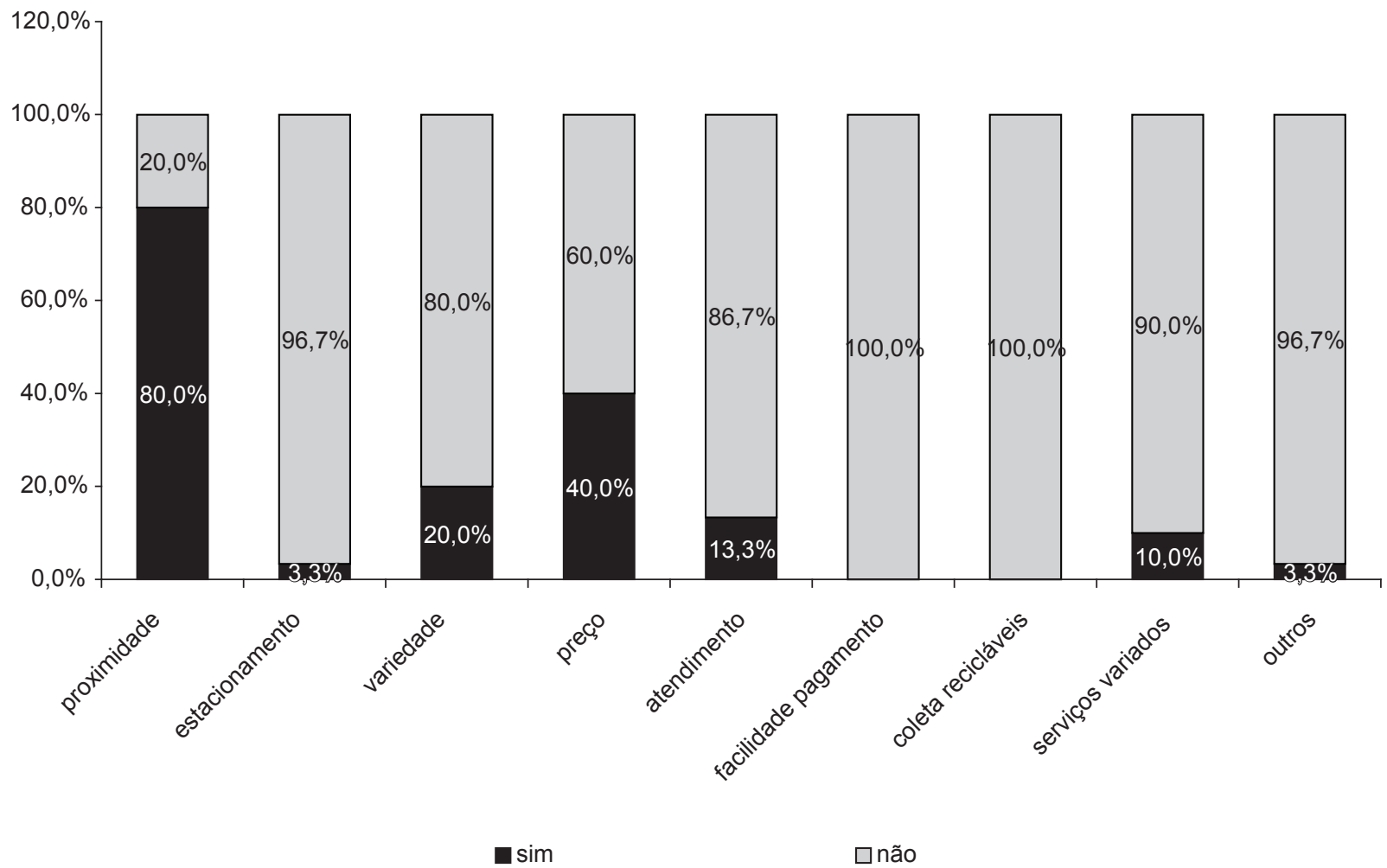

Figura 6. Fatores que influenciam a escolha do local de compra para os consumidores em São Paulo. Fonte: Dados da pesquisa. 
consumidor é o objetivo do marketing, pois pela manipulação do composto de marketing a empresa tem potencial para afetar o processo de compra, atuando nas variáveis determinantes na decisão de compra de seu consumidoralvo.

Pode-se observar também que a existência de pontos de coleta de embalagens recicláveis é o único fator que não influencia a decisão do comprador em Belo Horizonte. Em São Paulo, juntamente com o fator facilidade de pagamentos, esta variável não é indicada pelos clientes do hipermercado.

Pode-se concluir que este fator não influencia a escolha do local de compra em nenhuma loja analisada e, portanto, é difícil que este estímulo tenha aumentado o fluxo de pessoas nas lojas como assumido pelas empresas parceiras.

Para saber se os clientes do hipermercado reconhecem a coleta de embalagens como um serviço diferenciado, foi indagado se os entrevistados tinham tomado conhecimento dos pontos de coleta. A Tabela 6 mostra que $82,2 \%$ dos entrevistados no Rio de Janeiro sabem que há um ponto de coleta de embalagens de bebidas no hipermercado. Porém, em Belo Horizonte e São Paulo a maioria dos entrevistados, $73,3 \%$ e $66,7 \%$, respectivamente, desconhecem estes pontos de coleta no hipermercado.

Este fato pode ser explicado parcialmente pela existência da parceria entre a rede de hipermercados e a indústria de reciclagem de embalagens ter se iniciado na cidade do Rio de Janeiro, já em 2001, e, somente algum tempo depois, ter se expandido para outras capitais estaduais. Entretanto, este aspecto não foi aprofundado neste estudo.

Este cenário contrasta com o que as duas empresas (recicladora e hipermercadista), responsáveis pela coleta de embalagens de bebidas, esperavam que os Centros de Coleta trouxessem como benefícios. Era esperado que os centros de coleta associassem a imagem das empresas

Tabela 6. Nível de conhecimento dos centros de coleta pelos consumidores entrevistados.

\begin{tabular}{crrr}
\hline $\begin{array}{c}\text { Conhece os } \\
\text { Centros } \\
\text { de Coleta? }\end{array}$ & $\begin{array}{c}\text { Rio de } \\
\text { Janeiro }\end{array}$ & $\begin{array}{c}\text { Belo } \\
\text { Horizonte }\end{array}$ & São Paulo \\
\hline Sim & $82,2 \%$ & $26,7 \%$ & $33,3 \%$ \\
Não & $17,8 \%$ & $73,3 \%$ & $66,7 \%$ \\
Total & $\mathbf{1 0 0 , 0 \%}$ & $\mathbf{1 0 0 , 0 \%}$ & $\mathbf{1 0 0 , 0 \%}$ \\
\hline
\end{tabular}

Fonte: Dados da pesquisa. com a preservação do meio ambiente e que aumentasse o fluxo de pessoas nas lojas, principalmente.

O percentual de clientes entrevistados que utilizam os pontos de coleta também surpreendeu. A Tabela 7 mostra que, no Rio de Janeiro, apenas $22,2 \%$ do total de entrevistados entregam embalagens de alumínio e PET nos pontos de coleta da rede de hipermercados. Em São Paulo, este valor é ainda menor, 10,0\% dos entrevistados, e, em Belo Horizonte, temos o menor percentual, apenas $3,3 \%$ do total de entrevistados.

Muitos entrevistados alegaram que não utilizam o ponto de coleta do hipermercado, mas fazem a coleta seletiva no próprio condomínio em que residem. Algumas pessoas também afirmaram doar estas embalagens para cooperativas de catadores que recolhem este material, pois acham que assim estão contribuindo socialmente e não só para a preservação ambiental.

No Rio de Janeiro, observa-se uma distribuição uniforme entre as pessoas que afirmaram fazer uso dos pontos de coleta do hipermercado, desde muito frequientemente até aquelas que muito raramente utilizam os Centros de Coleta. É difícil fazer alguma inferência dos dados encontrados nas lojas de Belo Horizonte e São Paulo, devido ao número reduzido de pessoas que utilizam este serviço.

Por último, foi pedido aos entrevistados que já utilizaram os pontos de coleta uma avaliação do serviço por meio de uma escala likert. Esta escala classificava os serviços entre muito bom e muito ruim. Observou-se que o serviço é bem avaliado pelos clientes. No geral, as avaliações se concentraram em muito bom e bom.

\section{Considerações finais}

A pesquisa constatou que a logística reversa não é um fator de influência na decisão sobre o local de compra. Outros fatores como proximidade, preço e variedade dos produtos prevalecem nesta escolha, como encontrado por outros autores (Sirohi et al., 1998; Leszczyc et al., 2000; Furuta, 2002; Xavier, 2005). Além disso, muitos clientes do hipermercado desconhecem a existência dos pontos de coleta. Mesmo dentre aqueles que conhecem os Centros de Coleta são poucos os que fazem uso deste serviço. A coleta seletiva nos condomínios e a entrega de embalagens para cooperativas de catadores explicariam parcialmente esta situação.

Tabela 7. Percentual de entrevistados que utilizam os centros de coleta.

\begin{tabular}{lcccrr}
\hline \multicolumn{1}{c}{ Lojas } & Total de Entrevistados & Conhece os Centros de Coleta & Já utilizou este serviço & \% * & \% ** \\
\hline Rio de Janeiro & 45 & 37 & 10 & $22,2 \%$ & $27 \%$ \\
Belo Horizonte & 30 & 8 & 1 & $3,3 \%$ & $12,5 \%$ \\
São Paulo & 30 & 10 & 3 & $10,0 \%$ & $30 \%$ \\
Total & $\mathbf{1 0 5}$ & $\mathbf{5 5}$ & $\mathbf{1 4}$ & $\mathbf{1 3 , 3 \%}$ & $\mathbf{2 5 , 5 \%}$ \\
\hline
\end{tabular}

*Percentagem sobre o total de entrevistados; e **Percentagem sobre o total que conhece os Centros de Coleta. Fonte: Dados da pesquisa. 
Desta forma, pode-se concluir que os clientes do hipermercado não reconhecem a coleta de embalagens como um serviço diferenciado. Portanto, é difícil que o fluxo nas lojas tenha aumentado e que os clientes tenham se tornado mais fiéis em função da campanha empreendida pelas empresas.

A existência de um sistema logístico reverso não é um elemento qualificador e, sim, uma atividade ganhadora de pedido, pois ele oferece um serviço específico que, muitas vezes é determinante na escolha do fornecedor. No entanto, para a campanha de incentivo à reciclagem de embalagens ser mais eficiente e abrangente é necessário que a rede de hipermercados e a empresa recicladora despendam um maior esforço na divulgação dos Centros de Coleta e na motivação dos seus clientes para a campanha.

Como implicações gerenciais, este estudo conclui que as empresas podem alcançar uma vantagem competitiva sustentável por diferenciação da imagem da empresa e de re- dução de custos (no caso da empresa de reciclagem). Porém este processo deve ser acompanhado por fortes incentivos de promoção (propaganda, força de vendas, dentre outros), para contribuir para os resultados esperados na concepção da logística reversa. Este tipo de campanha é susceptível à conscientização por parte dos consumidores, bem como de sua percepção das vantagens em participar dela.

Entretanto, vale ressaltar as limitações desta pesquisa. Além da limitação devido à aleatoriedade da amostra, não foi possível estratificá-la com relação à renda familiar, escolaridade e local de residência para analisar se estes fatores influenciam a relação consumidor-coleta de embalagens. Também não se conhece o perfil do consumidor que realmente utiliza os Centros de Coleta do hipermercado. Além disso, não foi analisado se os clientes da rede hipermercadista associam a empresa com a preservação ambiental. Sugere-se que estas questões componham uma agenda de pesquisa específica a este assunto.

\section{Referências Bibliográficas}

BALLOU, R. H. Logística empresarial: transportes, administração de materiais e distribuição física. São Paulo: Atlas, 1993.

BEIGUELMAN, B. Curso prático de bioestatística. $4^{\circ}$ ed. Ribeirão Preto: Sociedade Brasileira de Genética,1996.

BERMAN, B.; EVANS, J. R. Retail management: a strategic approach. New York: Macmillan Publishing Company, 1989.

BRASIL. Ministério do Meio Ambiente. Conselho Nacional de Meio Ambiente. Resolução CONAMA No 258 de 26 de agosto de 1999. Publicação Diário Oficial da União: 02/12/1999. Brasília, 1999. Disponível em: <http://www. mma.gov.br/port/conama/res/res99/res25899.html> Acesso em: janeiro de 2004

CHAVES, G. de L. D. Diagnóstico da logística reversa na cadeia de suprimentos de alimentos processados no oeste paranaense. 2005. 124f. Dissertação (Mestrado em Desenvolvimento Regional e Agronegócio) Departamento de Economia, Universidade Estadual do Oeste do Paraná/Campus de Toledo. Toledo, 2005

CHRISTOPHER, M. Logística e gerenciamento da cadeia de suprimentos. São Paulo: Pioneira, 2001.

CHURCHILL, G. A. Marketing: criando valor para os clientes. 2 ed. São Paulo: Saraiva, 2003.

COMPROMISSO EMPRESARIAL PARA RECICLAGEM (CEMPRE). O mercado para reciclagem. Disponível em: <http://www.cempre.org.br>. Acesso em: novembro de 2006.
COUNCIL OF SUPPLY CHAIN MANAGEMENT PROFESSIONALS (CSCMP). Supply chain and logistics terms and glossary, 2005. Disponível em: <http://www.cscmp. org/Terms/glossary03.htm> Acesso em: janeiro de 2005.

DONOVAN, R.; ROSSITER, J. Store atmosphere: an experimental psychology approach. Journal of Retailing, v. 58. p. 34-37, 1982.

ENGEL, J.; BLACKWELL, R. D.; MINIARD, P. W. Comportamento do consumidor. Rio de Janeiro: LTC, 2000.

FURUTA, É. C. Razões de escolha de supermercados de vizinhança como local de compra. 2002. 97 f. Trabalho de Conclusão de Curso (Graduação em Administração de Empresas) - Faculdade de Economia, Administração e Contabilidade, Universidade de São Paulo. São Paulo, 2002.

HENDERSON, B. D. As origens da estratégia. In.: MONTGOMERY, C. A.; PORTER, M. E. Estratégia: a busca da vantagem competitiva. $6^{\circ}$ ed. Rio de Janeiro: Campus, 1998. p. 3-10.

HOFFMANN, R. Estatística para economistas. São Paulo: Biblioteca Pioneira de Ciências Sociais, 1980.

KOTLER, P.; ARMSTRONG, G. Princípios de marketing. Rio de Janeiro: LTC Editora, 1998.

KOTLER, P. Administração de marketing: a edição do novo milênio. Rio de Janeiro: Atlas, 2000.

LACERDA, L. Logística Reversa: Uma visão sobre os conceitos e as práticas operacionais. In: FIGUEIREDO, K. F.; FLEURY, P. F.; WANKE, P. (orgs.) Logística e gerenciamento da cadeia de suprimentos: planejamento 
do fluxo de produtos e dos recursos. São Paulo: Atlas, 2003. p. 475-483.

LEITE, P. R. Logística reversa: meio ambiente e competitividade. São Paulo: Prentice Hall, 2003.

LESZCZYC, P. T. L. P.; SINHA, A.; TIMMERMANS, H. J. P. Consumer store choice dynamics: an analysis of the competitive market structure for grocery stores. Journal of Retailing, v. 76, n. 3. p. 323-345, 2000.

MEYER, H. Many happy returns. The Journal of Business Strategy, 1999, v. 20, n. 4. p. 27-31.

MONTGOMERY, D. C. Design and analysis of experiments. 4 ed. New York: John Wiley \& Sons, 1997.

MOURA, T. L. de. Formato de varejo de alimentos: um estudo sobre as preferências do consumidor. 2005. 210f. Dissertação (Mestrado em Engenharia de Produção) - Departamento de Engenharia de Produção, Universidade Federal de São Carlos. São Carlos, 2005.

NOREK, C. D. Throwing it into reverse. DC Velocity, 2003. Disponível em: <http://dcvelocity.com/articles/january2003/returns.cfm> Acesso em: abril de 2004.

PETCORE - PET Containers Recycling Europe. PET in Europe. Disponível em: <http://www.petcore.org/euro intro_01.html> Acesso em: novembro de 2006.

PETER, J. P.; OLSON, J. C. Consumer behavior and marketing strategy. Irwin/McGraw-Hill: 1999.

PORTER, M. E. Estratégia competitiva: técnicas para análise de indústrias e da concorrência. Rio de Janeiro: Campus, 1986.
REVLOG. The European working group on reverse logistics. Disponível em: <http://www.fbk.eur.nl/OZ/REVLOG/Introduction.htm> Acesso em: janeiro de 2005.

ROGERS, D. S.; TIBBEN-LEMBKE, R. S. Going backwards: reverse logistics trends and practices. University of Nevada. Reno: CLM, 1998.

An examination of reverse logistics practices. Journal of Business Logistics, v. 22, n. 2, p. 129-148, 2001.

SAMARA, B. S.; BARROS, J. C. de. Pesquisa de mercado. São Paulo: Atlas, 2002.

SILVA, N. N., Amostragem Probabilística. São Paulo: EDUSP, 2001.

SIROHI, N.; MCLAUGHLIN, E. W.; WITTINK, D. R. A model of consumer perceptions and store loyalty intentions for a supermarket retailer. Journal of Retailing, v. 74, n. 2. pp 223-245, 1998.

SOLOMON, M. R. Consumer behavior: buying, having, and being. 4 ed. New Jersey: Prentice-Hall, 1999.

STEVEN, M. Networks in reverse logistics. In: DYCKHOFF, H.; LACKES, R.; REESE, J. Supply chain management and reverse logistics. Berlim: Springer, 2004.

WATSON, J. B. Psychology as the behaviorist views it. Psychological review, v. 20, pp 158-177,1913.

XAVIER, F. M. A Formulação da Estratégia de Operações como Fator de Melhoria da Competitividade no Varejo. 2005. $208 \mathrm{f}$. Tese (Doutorado em Engenharia de Produção) - Departamento de Engenharia de Produção, Universidade Federal de Santa Catarina. Florianópolis, 2005.

\title{
DO CONSUMERS VALUE RECYCLED PACKAGING COLLECTIONS? A CASE STUDY OF REVERSE LOGISTICS IN A RETAIL COMPANY
}

\begin{abstract}
The aim of this paper is to verify the role and relevance of recycled packaging Collection Centers as a factor of attracting customers to supermarkets. The analysis is based on a theoretical reference that has reverse logistics as a central concept. The literature affirms that reverse logistics are a result of the increasing concern of consumers about the environment, which, therefore, would tend to value organizations that were involved in recycling. To address these issues, research conducted on 105 customers from three of the retailer's hypermarkets was conducted in three capital cities (Rio de Janeiro/RJ, São Paulo/SP and Belo Horizonte/MG). Taking this into account, it was possible to point out that most of the retailer's customers in the Belo Horizonte and São Paulo stores are not aware of the existence of Collection Centers, unlike customers in the Rio de Janeiro store. Consequently, these Centers are not considered as an influence factor on the choice of the purchasing store. It is concluded that in order for the recycling incentive campaign to be broader and more efficient, it is necessary for the retailer and the recycling company to make a greater effort in advertising Collection Centers and in its customers' motivation towards the campaign. Thus, firms may have a sustainable competitive advantage by differentiating their company's image.
\end{abstract}

Keywords: reverse logistics, retailer, packaging collection. 